\title{
Spawanie laserowe mechanizmu siedzenia samochodowego
}

\section{Laser welding of car seat mechanism}

\section{Streszczenie}

W artykule przedstawiono wyniki badań połączeń spawanych elementów regulacji pochylenia oparcia siedzenia samochodowego wykonanych $z$ niskowęglowych stali niestopowych o grubości blachy $2 \div 4,5 \mathrm{~mm}$. Do spawania użyto lasera molekularnego $\mathrm{CO}_{2}$ w osłonie helu. Jakość połączeń spawanych oceniano na podstawie: prób wytrzymałościowych, pomiarów mikrotwardości oraz oceny geometrii złączy przez pomiar szerokości i głębokości wtopienia spoiny w badaniach metalograficznych. Badania wykazały dobrą jakość połączeń spawanych mechanizmu siedzenia samochodowego, co potwierdziło poprawność doboru parametrów technologii spawania laserowego.

\section{Wstęp}

Spawanie laserowe materiałów jest stosowane coraz częściej w krajowym przemyśle [1:5]. Elementy regulacji oparcia siedzenia samochodowego są łączone przez spawanie wiązką laserową z głębokim wtopieniem. Roztopiony materiał pod wpływem odrzutu odparowujących cząstek siły jest rozsuwany na boki i umożliwia penetrację wiązki w głąb materiału [6]. Firmą produkującą mechanizmy regulacji oparcia siedzenia samochodowego jest Zakład Mechanizmów Faurecia Wałbrzych Obok innych inwestorów przemysłu samochodowego, zakład produkuje w systemie just in time elementy mechanizmu regulacji dla światowych marek samochodowych.

\section{Mechanizm regulacji siedzenia samochodowego}

Elementy mechanizmu regulacji siedzenia samochodowego pokazano na rysunku 1.

Dr hab. inż. Zbigniew Mirski, prof. PWr - Politechnika Wrocławska, inż. Kamil Śpiewak

- Zakład Mechanizmów Faurecia Wałbrzych.

\section{Abstract}

The results of welding joints the car seat adjustment mechanism elements are given in the paper. The elements are made of low-carbon ordinary steel with thickness of sheets from 2 to $4.5 \mathrm{~mm}$. Welding process is carried out with a molecular $\mathrm{CO}_{2}$ laser with helium as a shielding gas. The quality of welding joints are estimated with strength tests, microhardness measurements, width and depth of the welds determined from metallographic studies. The investigation shown good quality of welding joint of elements of car seat mechanism, which confirmed good selection of the parameters of laser-welding.

Podstawowe elementy mechanizmu i ich opis przedstawiono w tablicy I, a skład chemiczny stali w tablicy II.

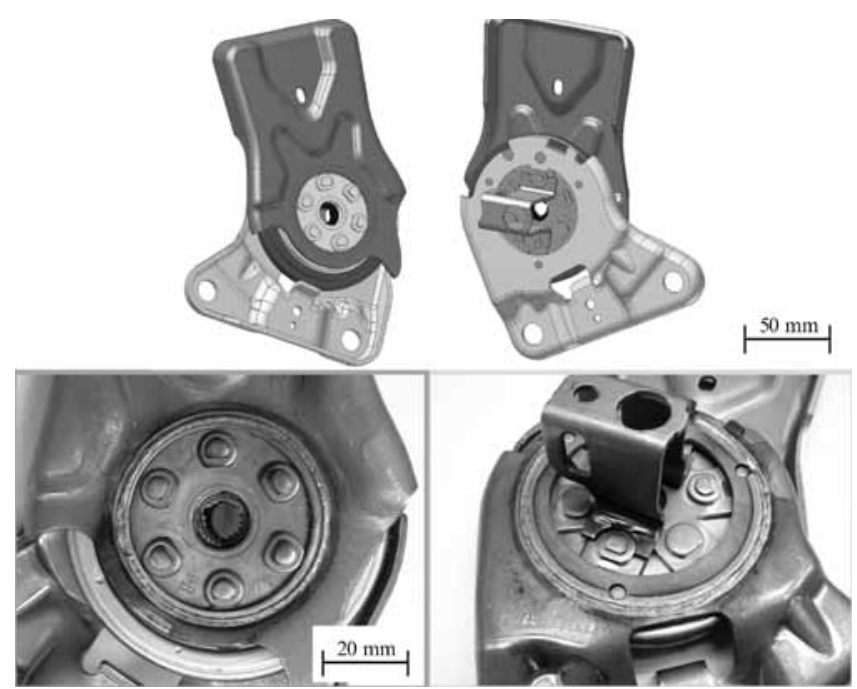

Rys. 1. Mechanizm regulacji siedzenia samochodowego [4, 5] Fig. 1. Mechanism for adjustment of the car seat $[4,5]$ 
Tablica I. Elementy składowe mechanizmu siedzenia samochodowego [5]

Table I. The component of car seat mechanism [5]

\begin{tabular}{|l|c|c|}
\hline \multicolumn{1}{|c|}{ Element } & Materiał (stal) \\
\hline $\begin{array}{l}\text { Ruchoma } \\
\text { płytka narożna I }\end{array}$ & $\mathrm{S} 700$ \\
\hline $\begin{array}{l}\text { Tarcza ruchoma II } \\
\text { reclinera }\end{array}$ & $\begin{array}{c}\text { C } 18 \mathrm{E} \\
\text { po procesie } \\
\text { węgloazotowania }\end{array}$ \\
\hline $\begin{array}{l}\text { Nieruchoma płytka } \\
\text { narożna III }\end{array}$ & S 700 \\
\hline $\begin{array}{l}\text { Tarcza stała IV } \\
\text { reclinera }\end{array}$ & S $420 \mathrm{MC}$ \\
\hline Wspornik V &
\end{tabular}

Tablica II. Skład chemiczny stali przeznaczonych na elementy mechanizmu wg PN-EN 10149-2:2000

Table II. Chemical composition of steel of components mechanism acc. to PN-EN 10149-2:2000

\begin{tabular}{|c|c|c|c|c|c|c|c|c|c|c|}
\hline \multirow{2}{*}{ Stal } & \multicolumn{10}{|c|}{ Skład chemiczny, \% wag. (reszta Fe) } \\
\hline & C & $\mathrm{Si}$ & $\mathrm{Mn}$ & $P$ & S & $\mathrm{Nb}$ & V & $\mathrm{Al}$ & $\mathrm{Ti}$ & $\mathrm{Cr}$ \\
\hline S 700 & 0,12 & 0,6 & 2,1 & 0,025 & 0,015 & 0,09 & 0,2 & 0,015 & 0,22 & - \\
\hline S 500 & 0,12 & 0,5 & 1,7 & 0,025 & 0,015 & 0,09 & 0,2 & 0,015 & 0,15 & - \\
\hline S 420MC & 0,12 & 0,5 & 1,6 & 0,025 & 0,015 & 0,09 & 0,2 & 0,015 & 0,15 & - \\
\hline C $18 \mathrm{E}$ & $\begin{array}{c}0,17 \div \\
0,22\end{array}$ & $\begin{array}{l}0,15 \\
\div 0,3\end{array}$ & $\begin{array}{c}0,6 \div \\
0,8\end{array}$ & 0,025 & 0,015 & - & - & 0,02 & - & 0,2 \\
\hline
\end{tabular}

\section{Stanowisko do spawania laserowego i parametry procesu}

Do połączenia elementów użyto lasera molekularnego $\mathrm{CO}_{2}$ ROFIN DC 060 o mocy $6 \mathrm{~kW}$. Emituje on niewidoczne dla ludzkiego oka, leżące $w$ dalekiej podczerwieni, równoległe i monochromatyczne promieniowanie o długości fali 10,6 $\mu \mathrm{m}$. Ośrodkiem czynnym tego lasera jest gaz Premix zawierający obok dwutlenku węgla także tlenek węgla, azot, tlen, ksenon i hel [7].

Do osłony powstającej spoiny zastosowano hel o czystości $\geq 99,999 \%$ obj., który w strefę spawania jest doprowadzany w ilości $20 \mathrm{dm} / \mathrm{min}$ pod ciśnieniem 1 1 1,5 bar. Prędkość spawania stalowych elementów mechanizmu regulacji siedzenia wynosiła $2,2 \div 2,8 \mathrm{~m} / \mathrm{min}$, w zależności od rodzaju stali i grubości spawanych elementów $[4,5]$.

Stanowisko spawania obejmuje dwie pozycje, które obsługuje głowica laserowa (rys. 2). Do każdego $z$ nich elementy spawane są dostarczane na paletach.

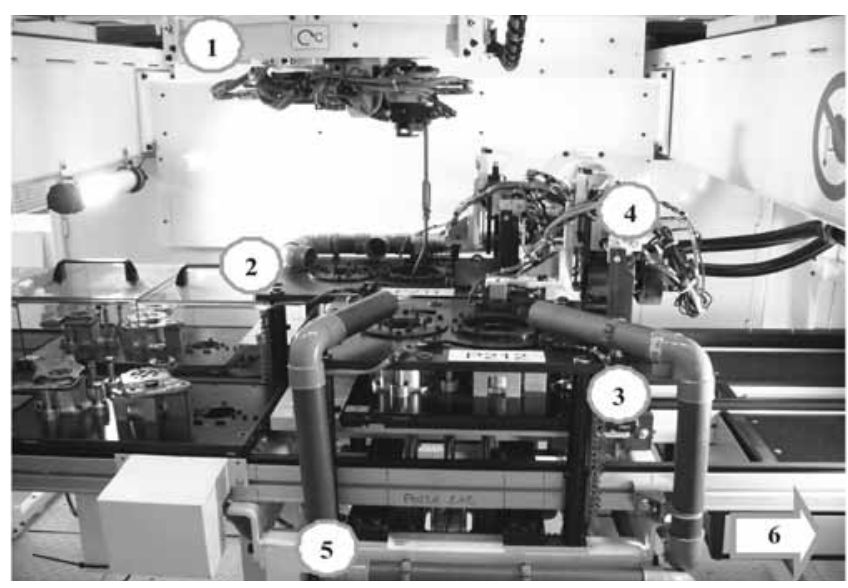

Rys. 2. Stacja spawania laserowego: 1 - głowica spawalnicza poruszająca się wzdłuż trzech osi i obracająca się wokół dwóch osi, 2 - stanowisko spawalnicze $\mathrm{nr}$ 1, 3 - stanowisko spawalnicze $\mathrm{nr} 2$, 4 - manipulator, 5 - instalacja odciągowa gazów spawalniczych, 6 - kierunek ruchu transportera palet [7]

Fig. 2. Set-up of laser welding: 1 - welding heat moving along three axis and rotating around two axis, 2 - the place of welding no. 1 , 3 - the place of welding no. 2, 4- manipulator, 5 - installation of weld gases extractor, 6 - direction of the palettes movement [7]

Ładowanie elementów na paletę jest uporządkowane. Są na niej 4 pozycje załadowcze (A, B, C i D), w których umieszcza się poszczególne elementy (rys. 3).

Wymienione pozycje oznaczają: pozycja A - ruchoma płytka narożna na zespawanym reclinerze z nieruchomą płytką narożną i wspornikiem od dołu, pozycja B - nieruchoma płytka narożna na tarczy stałej reclinera, pozycja $C$ - wolna - wykorzystywana do innych zadań, pozycja $D$ - wspornik [7].

Podczas spawania mechanizmu najpierw spawana jest nieruchoma płytka $z$ tarczą stała reclinera. Następnie jest do nich spawany wspornik. Kolejnym etapem jest zdjęcie pospawanego zespołu trzech elementów z palety (pozycja B), obrócenie tarczą ruchomą reclinera do góry i ułożenie go na pozycji $A$, gdzie dospawana jest płytka ruchoma do ruchomej tarczy reclinera.

Przyjęto następujące kryteria dla połączeń spawanych $[4,5]$ :

- rodzaj złącza: zakładkowe z liniową spoiną przetopową,

- szerokość wtopienia spoiny na granicy dwóch materiałów: powyżej $1 \mathrm{~mm}$,

- głębokość wtopienia spoiny w drugim materiale $0,5 \div 2,5 \mathrm{~mm}$.

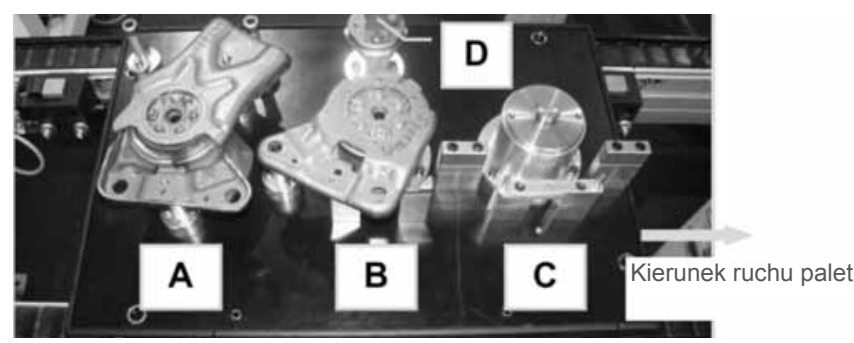

Rys. 3. Załadunek elementów mechanizmu na paletę [5]

Fig 3. Parts of mechanism on the palette loading [5] 


\section{Próby wytrzymałościowe}

Przed próbą wytwarzania mechanizmów wykonano testy na złączach próbnych. Stanowiły je: połączenie dwóch trójkątnych płytek grubości 2,5 i 4,5 mm, wykonanych ze stali S 700 i C 18 E po procesie węgloazotowania. Oba elementy trójkątne zespawano, a następnie ścinano spajające ich połączenie na maszynie wytrzymałościowej. Podczas tego testu jedna płytka była unieruchomiona, a druga była obciążana względem osi otworu centralnego. Widok ściętego połączenia spawanego pokazano na rysunku 4 . Wartość momentu ścinającego uzyskanego $w$ tej próbie wynosiła 611 daNm (rys. 5).

Po wykonaniu prób wytrzymałościowych na złączach próbnych, które potwierdziły poprawność doboru parametrów spawania, przeprowadzono podobne próby na zespawanych elementach mechanizmu. Próby te wykonano dwuetapowo. Najpierw zablokowane mechanizmy poddano oddziaływaniu siły działającej w kierunku A, a następnie w kierunku B (rys. 6). Przykładowy wynik ścinania mechanizmu w kierunku A pokazano na rysunku 7.

Wynik testu niszczącego w kierunku działania siły A osiągnął wartość 241 daNm, powyżej wartości dopuszczalnej równej 170 daNm. Na rysunku 8 pokazano mechanizm zniszczenia $w$ tej próbie, ruchoma płytka narożna została oderwana od ruchomej tarczy reclinera.

Podczas testu niszczącego elementy mechanizmu w kierunku działania siły B moment ścinający osiągnął wartość 239 daNm, powyżej wartości dopuszczalnej 190 daNm (rys. 9).

Podczas tej próby niszczącej w pospawanych elementach mechanizmu została również oderwana ruchoma płytka narożna. Na rysunku 10 widoczny jest obszar złomu po ściętej spoinie na całym obwodzie tarczy ruchomej reclinera.

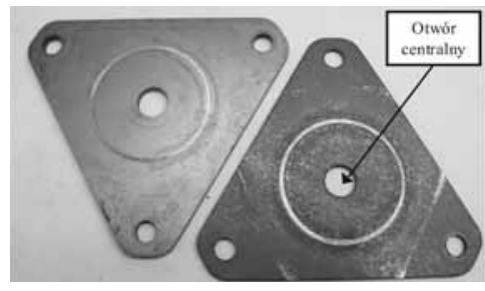

Rys. 4. Trójkątne płytki po teście niszczącym $[4,5]$

Fig. 4. Triangular plates after destructive test $[4,5]$

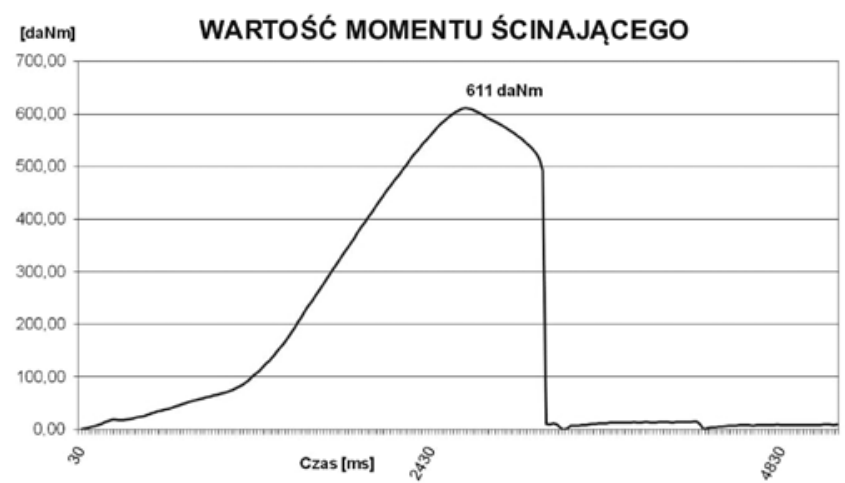

Rys. 5. Wynik testu niszczącego połączenia płytek trójkątnych $[4,5]$ Fig. 5. Result of destructive test of joint of triangular plates [4, 5]

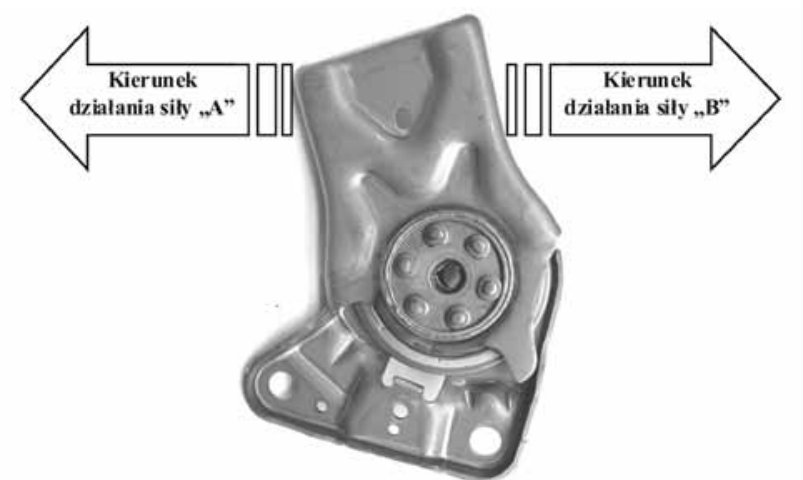

Rys. 6. Kierunek działania siły w testach wytrzymałościowych mechanizmu $[4,5]$

Fig. 6. Direction of the force in destructive tests of the mechanism $[4,5]$

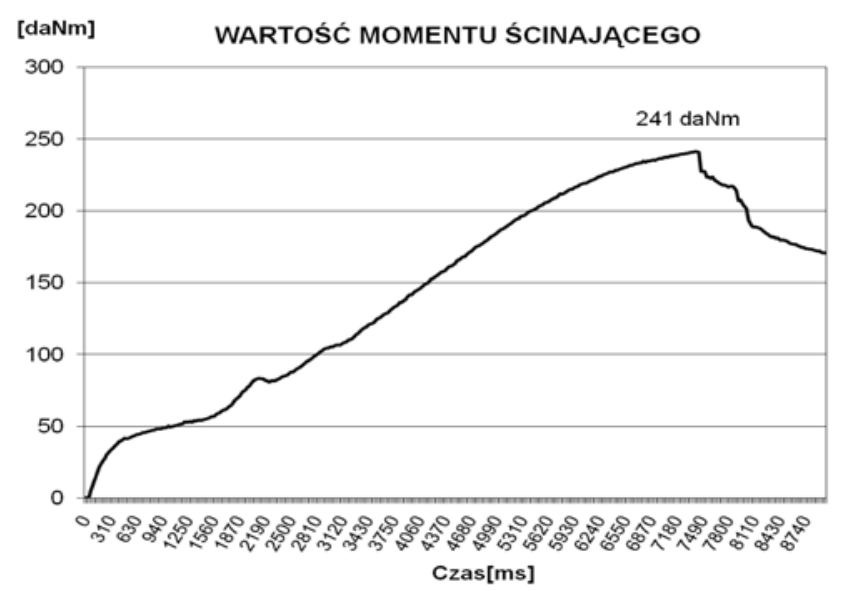

Rys. 7. Wykres testu niszczącego w stronę działania siły $A[4,5]$ Fig. 7. The plot of destructive test in direction $A$ of the force $[4,5]$

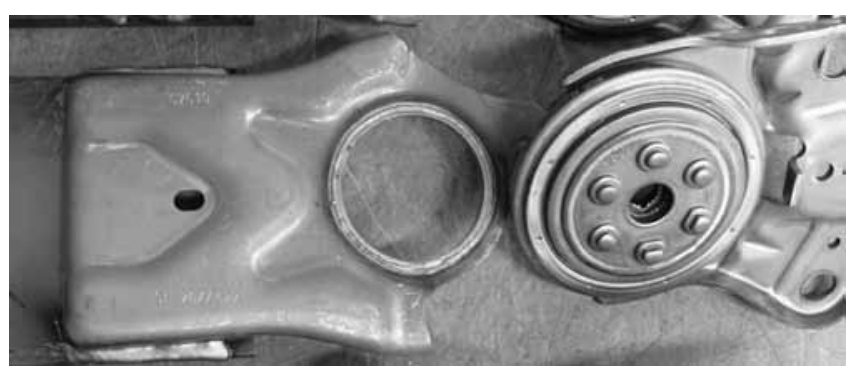

Rys. 8. Mechanizm po teście niszczącym w stronę działania siły $A$ $[4,5]$

Fig. 8. Mechanism after destructive test in direction $\mathrm{A}$ of the force $[4,5]$

\section{Badania metalograficzne}

Badania metalograficzne połączeń spawanych wykonano w celu weryfikacji warunków spawania, przekładających się na określone szerokości i głębokości przetopu spoin. Badania wykonano na urządzeniu Welding Expert po uprzednim przygotowaniu próbek. Przygotowanie polegało na pocięciu pospawanego mechanizmu w miejscach oznaczonych na rysunku 11 na fragmenty.

Wycięte próbki poddano szlifowaniu na papierach ściernych i polerowaniu, a następnie trawieniu chemicznemu odczynnikiem na bazie chlorku 


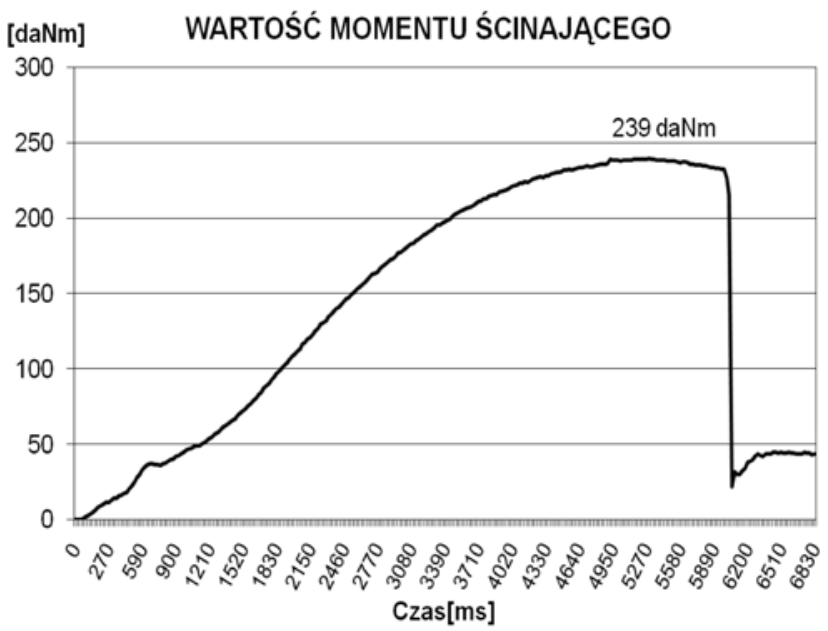

Rys. 9. Test niszczący dla siły B $[4,5]$

Fig. 9. The plot of destructive test in direction $B$ of the force $[4,5]$

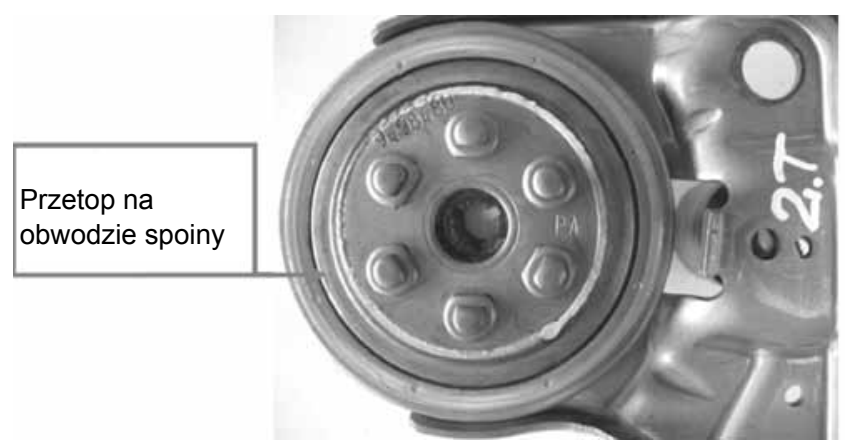

Rys. 10. Mechanizm po teście niszczącym w kierunku działania siły $B[4,5]$

Fig. 10. Mechanism after destructive test in direction $B$ of the force $[4,5]$

żelaza (30\%). Tak przygotowane zgłady metalograficzne układano na szybie urządzenia Welding Expert w celu oceny szerokości i głębokości przetopu spoiny (rys. 12).

Welding Expert umożliwia pomiar próbek $z$ dokładnością do $60 \mu \mathrm{m}$. Urządzenie jest wyposażone w układ optycznej zmiany wielkości obrazu sterowany elektronicznie. Przy każdej zmianie ogniskowej program automatycznie oblicza współczynnik kalibracji. Za pomocą tego oprogramowania i urządzenia można szybko zmierzyć grubość materiałów, wysokość względem przeciwprostokątnej trójkąta równoramiennego wpisanego w przekrój spoiny pachwinowej, głębokość i szerokość wtopienia spoiny, szerokość strefy wpływu ciepła oraz zidentyfikować wszelkie niezgodności w przekroju poprzecznym spoiny. Wynik pomiaru można zapisać w arkuszu kalkulacyjnym [8].

Wyniki pomiarów geometrii spoiny w wybranych miejscach pomiarowych pokazano na rysunku 13.

Pomiary głębokości wtopienia spoiny w drugi element oraz szerokości spoiny na granicy ich połączenia wykazały spełnienie narzuconych wymagań.
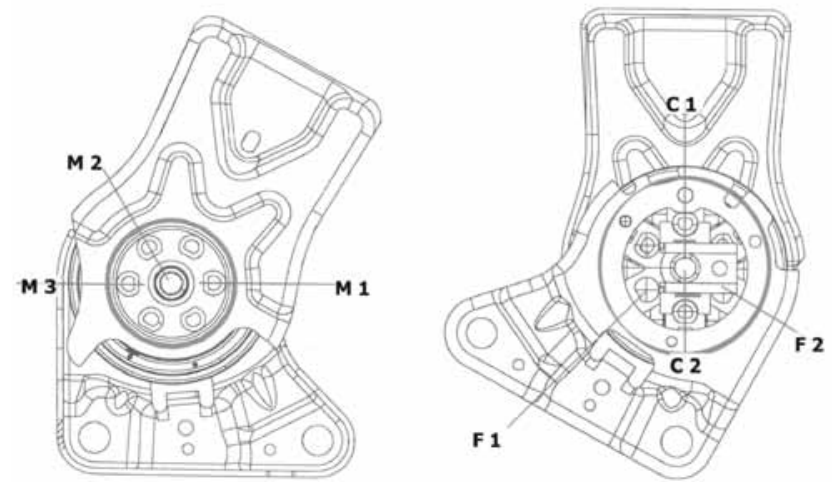

Rys. 11. Miejsca pomiaru spoin $[4,5]$

Fig. 11. The place of the welds measurement $[4,5]$

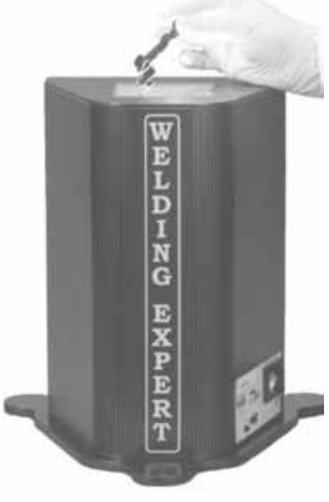

Rys. 12. Urządzenie pomiarowe Welding Expert [8]

Fig. 12. The Welding Expert measuring apparatus [8]

Spoina w punkcie M2

$\mathrm{g}-0,9 \mathrm{~mm}$

$\mathrm{hr}-1,4 \mathrm{~mm}$

\section{Spoina w punkcie F2 $\mathrm{g}-1,1 \mathrm{~mm}$ $\mathrm{hr}-1,6 \mathrm{~mm}$}
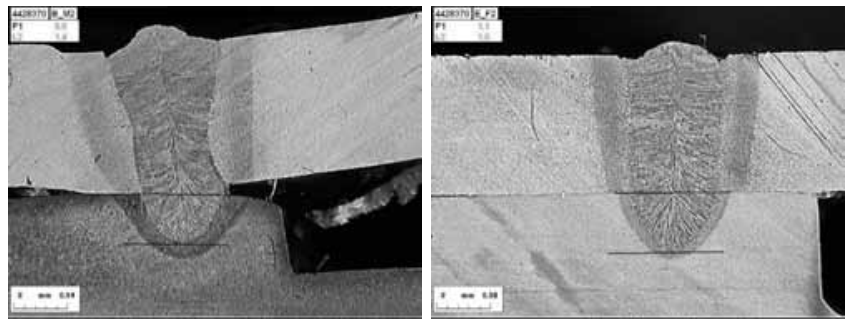

Spoina w punkcie $\mathrm{C} 1$

$\mathrm{g}-1,3 \mathrm{~mm}$

$h r-1,8 \mathrm{~mm}$

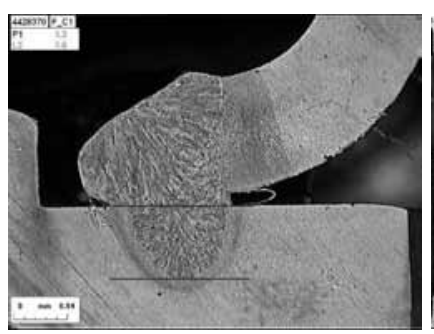

Spoina w punkcie C2

$\mathrm{g}-1,5 \mathrm{~mm}$

$\mathrm{hr}-1,4 \mathrm{~mm}$

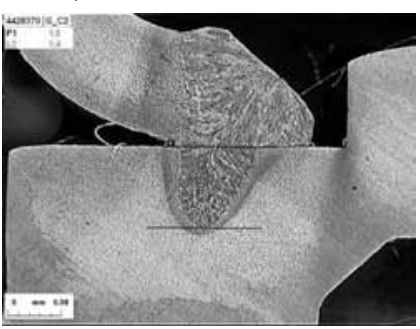

Rys. 13. Wyniki pomiarów geometrii spoin w wybranych miejscach pomiarowych: M2, F2, C1 i C2 [4, 5]; g - głębokość wtopienia w dolny element, wymagana wartość $0,5 \div 2,5 \mathrm{~mm}, h r$ - szerokość spoiny na granicy elementów, wymagana wartość $>1 \mathrm{~mm}$

Fig 13. The results of the joints geometry measurements in places: M2, F2, C1 and C2 [4, 5]; g - fusion depth in the bottom element, required value $0,5 \div 2,5 \mathrm{~mm}, h r$ - weld width in the elements boundary, required value $>1 \mathrm{~mm}$ 


\section{Pomiary mikrotwardości}

Pomiary mikrotwardości połączeń spawanych mechanizmów wykonano metodą Vickersa, przy obciążeniu piramidki diamentowej $50 \mathrm{~g}$. mikrotwardościomierzem FM-100. Linie pomiarowe na przykładowym złączu spawanym dwóch trójkątnych płytek o grubości 2,5 i 4,5 mm, wykonanych ze stali S 700 i C 18 E po procesie węgloazotowania pokazano na rysunku 14 , a wyniki pomiarów wzdłuż tych linii zamieszczono w tablicy III.

Wyniki pomiarów mikrotwardości wskazują, że złącze spawane promieniem lasera wykazuje utwardzenie w strefie wpływu ciepła i w spoinie. Twardość materiału rodzimego obu spawanych elementów wynosi poniżej $300 \mathrm{HV0,05}$. W strefie wpływu ciepła twardość w górnym materiale wzrasta o ok. $40 \mathrm{HV0,05,} \mathrm{w} \mathrm{dol-}$ nym zaś o $200 \mathrm{HV0}, 05$. Twardość spoiny przy granicy wtopienia wynosi ok. 436 HV0,05 w środku średnio 412 HV0,05 w części należącej do górnego materiału. W dolnej części spoiny twardość w pobliżu granicy wtopienia kształtuje się na poziomie $454 \div 463 \mathrm{HV} 0,05$,

Tablica III. Wyniki pomiarów mikrotwardości HV0,05 obszarów złącza spawanego $[4,5]$

Table III. The results of measurements of the microhardness HV0.05 of welded joints areas $[4,5]$

\begin{tabular}{|c|c|c|c|c|c|c|c|c|c|}
\hline $\begin{array}{c}\text { Miejsce } \\
\text { pomiaru }\end{array}$ & \multicolumn{3}{|c|}{$\begin{array}{c}\text { Materiał } \\
\text { rodzimy }\end{array}$} & \multicolumn{3}{c|}{$\begin{array}{c}\text { Strefa wpływu } \\
\text { ciepła }\end{array}$} & \multicolumn{3}{c|}{ Spoina } \\
\hline nr pomiaru & 1 & 2 & 3 & 4 & 5 & 6 & 7 & 8 & 9 \\
\hline linia 1 & 286 & 286 & 290 & 290 & 315 & 320 & 432 & 420 & 432 \\
\hline linia 2 & 286 & 283 & 295 & 334 & 323 & 334 & 436 & 404 & 424 \\
\hline linia 3 & 260 & 272 & 378 & 463 & 473 & 472 & 454 & 445 & 463 \\
\hline
\end{tabular}

\section{Podsumowanie}

Opracowana technologia spawania laserowego mechanizmu oparcia siedzenia samochodowego w firmie Faurecia w Wałbrzychu wykazała na podstawie badań poprawnie dobrane parametry spawania laserem molekularnym $\mathrm{CO}_{2}$ czterech elementów stalowych, stanowiących części składowe mechanizmu siedzenia samochodowego. Zarówno testy a środek spoiny wykazuje wartość $445 \mathrm{HV0}, 05$. Największą twardość osiągnięto dla wartości 473 HV0,05 w strefie wpływu ciepła dolnego materiału (C $18 \mathrm{E} \mathrm{po}$ węgloazotowaniu). Mimo znacznego utwardzenia spoiny i strefy wpływu ciepła nie zaobserwowano pęknięć w połączeniach spawanych mechanizmów.

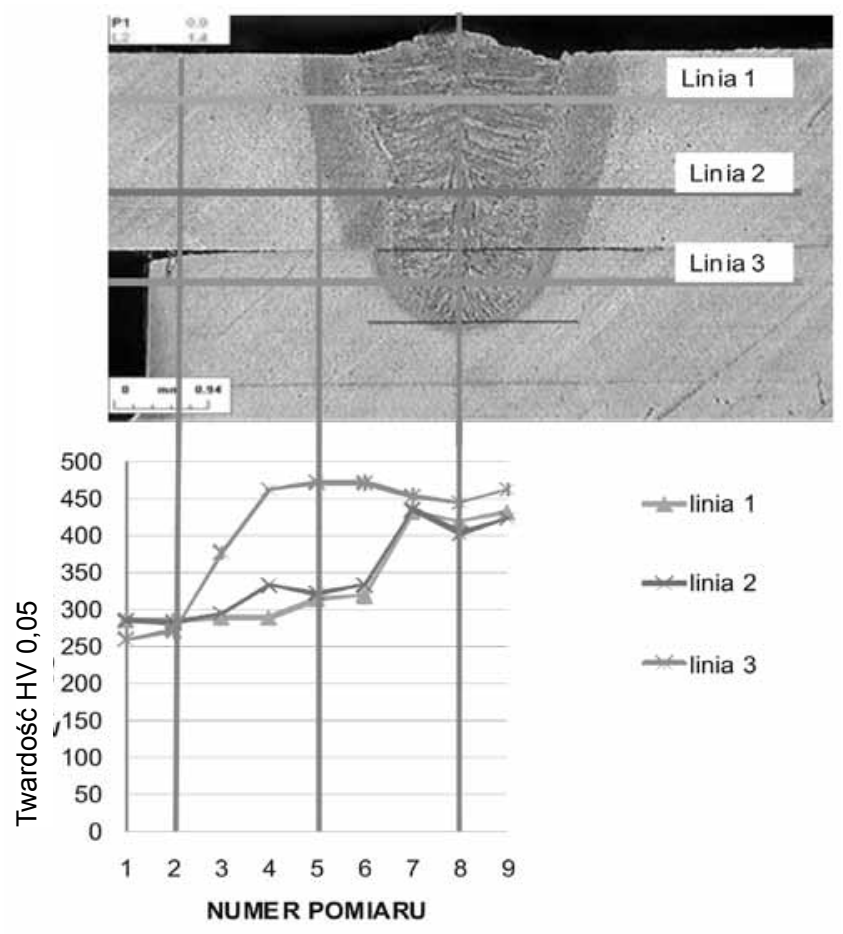

Rys. 14. Linie pomiarowe i rozkład mikrotwardości HV0,05 przykładowego złącza spawanego $[4,5]$

Fig. 14. The measuring lines and distribution of the microhardness HV0.05 of typical welded joint $[4,5]$

\section{Literatura}

[1] Poradnik Inżyniera. Spawalnictwo, tom 2 (pod red. J. Pilarczyka), WNT, Warszawa 2005.

[2] Pilarczyk J., Banasik M., Stano S., Dworak J.: Spawanie laserowe $z$ materiałem dodatkowym i mechanicznym śledzeniem złącza, Przegląd Spawalnictwa, 12/2011, s. 9-14.

[3] Mirski Z., Granat K., Stano S.: Możliwości spajania węglików spiekanych ze stalą wiązką lasera, Przegląd Spawalnictwa, 12/2011, s. $15-20$.

wytrzymałościowe, polegające na ścinaniu połączeń spawanych mechanizmów, jak i pomiary geometrii spoin na podstawie badań metalograficznych przyniosły zadowalające wyniki świadczące o dobrej jakości złączy spawanych w produkowanych siedzeniach samochodowych.

Artykuł powstał na podstawie pracy dyplomowej inż. Kamila Śpiewaka [4], który otrzymał I nagrodę w 2011 roku, w XI edycji Ogólnopolskiego Konkursu o Nagrode i Dyplom Prezesa SIMP na najlepszą prace dyplomową o profilu mechanicznym, obronioną w państwowej wyższej uczelni technicznej, organizowanego pod patronatem Pani Barbary Kudryckiej - Minister Nauki i Szkolnictwa Wyższego. 